\section{CARTAGO E AS TRANSFORMAÇÕES DA TOPOGRAFIA MORTUÁRIA NA ANTIGUIDADE TARDIA (SÉC. IV-VII): EM BUSCA DE CONEXÓES NOVAS}

\author{
Rafael A. Monpean \\ Pedro Paulo A. Funari ${ }^{* \star}$
}

RESUMO: Nosso objetivo neste artigo é abordar as transformaçōes das relações entre as cidades e suas respectivas áreas de sepultamento no decorrer da Antiguidade Tardia (séc. IV-VII) na África do Norte, a partir de um estudo de caso: a cidade de Cartago. Com o apontamento de determinadas mudanças materiais, através da interpretação de estudos sobre sítios específicos localizados dentro e fora dos muros de Cartago, intenta-se observar a dinâmica das relações para com a morte e os mortos nesta conjuntura. Assim, sublinha-se a multiplicidade de abordagens suscitadas pelos estudos da materialidade mortuária.

PALAVRAS-CHAVE: Topografia mortuária; África do Norte; Antiguidade tardia; Cartago.

CARTHAGE AND THE TRANSFORMATIONS OF MORTUARY TOPOGRAPHY IN LATE ANTIQUITY (C. IV-VII): SEARCHING FOR NEW CONECTIONS

\begin{abstract}
The paper aims at studying the changes in ancient towns in relation to dead bodies and remains, during the late antique period, from the 4th to the 7 th c., in northern Africa, using Carthage as a study case. Studying material changes, through the analysis of specific archaeological sites inside and outside the walls in Carthage, the paper studies social relations relating to death and mortuary practices. The paper stresses a variety of approaches to understanding mortuary materiality.
\end{abstract}

KEYWORDS: Mortuary topography; North Africa; Late Antiquity; Carthage.

\footnotetext{
* Mestrando em História

Cultural na Universidade

Estadual de Campinas\

Brasil. E-mail: rafael.

monpean@gmail.com
}

** Professor Titular da Universidade Estadual de Campinas\Brasil. E-mail: ppfunari@uol.com.br 
Difícil determinar a Antiguidade Tardia, tema deste artigo. Como lembrava Peter Brown (1998, p. 140), desde o século II d.C. o código penal do Império Romano só reconhecia a oposição brutal entre honestiores e humiliores, entre e ricos e pobres. $\mathrm{O}$ mesmo Brown recua, em aspectos antropológicos, até mesmo ao século I d.C. (BROWN, 1990, p. 244) o início de mudanças que iriam caracterizar o mundo antigo pelos séculos seguintes. As transformações acentuaram-se com as guerras civis das décadas centrais do século III, para conformar novas realidades a partir do início do século seguinte, como atestam periodizaçôes adotadas por autores recentes, como Júlio César Magalhães de Oliveira (2012). Aspecto essencial dessa mudança consistiu nas novas relações entre política e religião (PUGLISI, 1981) e mesmo numa certa dissociação do poder político da estrutura imperial, como propôs Henry Chadwick (2001, p. 109) em estudo clássico sobre Agostinho. Mais do que isso, como propôs há pouco Paul S. Johnson (2012), as evidências materiais ou arqueológicas são essenciais para estudar as características e mudanças entre o Principado e a Antiguidade Tardia, em explícita contraposição às posições weberianas e centradas nas fontes literárias da elite, tal como propostas pelo que denomina de escola de Cambridge (JOHNSON, 2012, p. 28-31).

Neste contexto, cremos ser fundamental uma afirmação que guiará todo o percurso que será traçado aqui: observar as práticas mortuárias no decorrer da Antiguidade tardia e sua conexão com a organização da topografia urbana é observar uma das relações marcantes e distintivas para a própria formulação deste recorte temporal, assim como para estabelecer seus limites cronológicos (IVISON, 1996). De modo bem esquemático, estas relações são estudadas de duas maneiras: diretas e indiretas. Diretas no sentido de observarem a questão da prática mortuária de modo pontual, seus efeitos de sentido produzidos, ou seja, sua relação com os problemas relacionados à memória, à demografia, à alimentação e às formas de vida social neste período. Indiretas no que tange aos estudos que acabam por tocar a questão mortuária por conta de outros aspectos considerados como principais, por exemplo: o estudo do culto dos mártires, o impacto da difusão do cristianismo, a 
transformação da paisagem urbana ou mesmo para se estabelecer o fim deste mundo antigo.

Contudo, advertirmos que, embora haja uma diferenciação do foco central entre o que identificamos como modos diretos e indiretos de se observar a questão mortuária na Antiguidade Tardia, ambos os aspectos abordados são indissociáveis. Isto porque não se pode observar as práticas mortuárias como um sistema autônomo e dissociável das condições de produção das quais emergiram. Do mesmo modo que é impossível analisar todas as características que envolvem sua emergência. Em resumo, é importante indicar que toda observação deste fenômeno, tal como de qualquer outro, depende de recortes específicos, de fontes específicas e de perspectivas teóricas específicas.

\section{Historiografia e ArQUeOlogia}

$\mathrm{Na}$ escolha de qualquer recorte específico é sempre preciso levar em conta as fontes que serão utilizadas. Para o estudo das práticas mortuárias que se desenvolvem do século IV ao VII, ou mesmo até o século VIII, as fontes textuais não são abundantes. Entretanto, não é apenas por este fator que devemos recorrer à diversidade das fontes. $\mathrm{O}$ problema que nos é colocado não se refere somente a "fechar lacunas" nas histórias que nos dispomos a contar. Ele vai além. A diversidade documental nos permite "contrastar, contrapor e completar as informaçōes fornecidas pela tradição textual" (FUNARI; GARRAFFONI, 2007, p. 4). Em outras palavras, com a diversidade dos testemunhos possíveis acerca de um mesmo tópico, podemos compor uma história que explicite os conflitos entre forças contrárias que estão em diálogo numa dada circunstância, ou mesmo re-apropriações ou re-significações de um sentido atribuído de modo prévio como universal (SMALL, 1999; FUNARI, 2006; MAGALHĀES DE OLIVEIRA, 2011).

Nesse sentido, se por cultura material entendemos todos os aspectos da materialidade produzida pelo gênero humano (FUNARI, 2006, p. 85), seu uso é imprescindível para o estudo da prática mortuária. As práticas mortuárias sempre deixam vestígios de sua ação, quer sejam de curta, média ou longa duração. E é a partir destes indícios de modos de ação 
1. Um panorama dos estudos sobre as cidades da região da África do Norte de fins do século passado pode ser encontrado em

Mattingly e Hitchner

(1995, p.177-180).

2. Uma discussão bibliográfica sobre as alterações da teoria e da prática arqueológica a respeito da Antiguidade tardia é realizada por Lavan (2003).

3. É o que pode ser encontrado em alguns dos artigos das coletâneas organizadas por Rich (1992), Christie e Loseby (1996), e Brogiolo e WardPerkins (1999). materializados em vestígios que buscamos interpretar e compreender os significados atribuídos a estas práticas (RIBEIRO, 2007, p. 19). Portanto, a nosso ver, o panorama dos estudos historiográficos das práticas mortuárias, em especial da Antiguidade tardia, não pode prescindir do diálogo com os estudos arqueológicos.

Podemos observar que quando Averil Cameron (1993, p. 157) alertava sobre o grande número de obras publicadas a respeito das cidades do Mediterrâneo antigo e tardio, a historiadora apontava que uma das principais razôes deste aumento estava relacionada com o desenvolvimento da Arqueologia, tanto de suas técnicas de escavação quanto da quantidade de trabalhos que enfocavam o mundo das cidades do fim da Antiguidade. ${ }^{1}$ De lá para cá muito mais pesquisas foram realizadas e publicadas. Solidificou-se uma ampla área de estudos em torno da questão citadina e das práticas e teorias arqueológicas para abordá-las, com posiçōes distintas sobre o destino das cidades dos, no mínimo, anos 300 aos 800. ${ }^{2}$ Esse aumento trouxe consigo uma intensificação das preocupaçôes a respeito das práticas mortuárias e de suas relações com a cidade, o que resultou em inúmeras publicações, na maioria arqueológicas, sobre a questão. ${ }^{3}$

É no interior desses diálogos - da Arqueologia com a Historiografia, da prática mortuária com a cidade -, que inserimos nosso artigo, que mais toma a forma de um breve ensaio dentro deste panorama de estudos.

TOPOGRAFIA URBANA E TOPOGRAFIA MORTUÁRIA: AS TRANSFORMAÇÓES NA CIDADE DE CARTAGO ENTRE OS SÉCUlOS IV E VII

A escolha da cidade de Cartago para observar as transformações da paisagem urbana em relação à topografia mortuária deve-se a dois motivos principais. $\mathrm{O}$ primeiro se deve ao fato de Cartago ter sido uma das mais importantes cidades do Mediterrâneo antigo, megalópole e principal cidade da África romana. O segundo é devido aos trabalhos arqueológicos realizados desde os anos 1970, a cidade transformou-se num verdadeiro laboratório da arqueologia urbana na segunda metade do século XX, no contexto da campanha para salvaguarda 
do sítio promovida pela UNESCO (FUMADÓ ORTEGA, 2009, p. 147-202).

Para utilizarmos as informações disponibilizadas pelos autores nos quais embasamos nosso levantamento da evidência material, tentamos fazer um pequeno esquema dos sepultamentos que eles indicam, assim como a referência, quando possível, das escavações, ou as interpretações nas quais se baseiam para comentar sobre estes mesmos sepultamentos. Com isso, esperamos poder compreender, de modo geral, a modificação na paisagem urbana de acordo com a topografia mortuária no decorrer dos séculos IV-VII e, em particular, discuti-la segundo a escolha de algumas localizaçôes particulares da Cartago do período tardio: o porto circular, o odeão e a região do circo máximo.

É importante alertar que devemos estar atentos às dificuldades encontradas, de modo geral, no sítio de Cartago. Os primeiros cuidados estão relacionados à dificuldade de estabelecer uma datação precisa e, por conseguinte, estabelecer uma cronologia dos fenômenos sucessivos. Isto ocorre devido às antigas escavaçōes realizadas na virada dos séculos XIX e XX que, por priorizarem determinados indícios - como "desenterrar" a cidade romana ou a cidade púnica -, relegaram outros considerados de menor importância - por exemplo, no nosso caso, as práticas mortuárias de períodos mais tardios. São estes problemas que teremos em mente quando observarmos, em especial, a região do odeão.

Lembremos que na cidade clássica, o pomerium delimitava uma nítida separação entre a cidade dos vivos (polis) e a cidade dos mortos (necropolis). O pomerium consistia em um limite sagrado das cidades em cujo interior era proibido enterrar os mortos (FUNARI, 2003, p. 44). No mundo romano esta divisão era uma tradição que estava presente desde a memória da fundação da cidade de Roma (GRANDAZZI, 2010, p. 19 e 114). Mas também há indícios que nos permitem afirmar que esta delimitação entre espaços dos vivos e dos mortos existia de modo semelhante, numa longa duração, na tradição púnica do Norte da África, como o próprio caso da cidade de Cartago (LANCEL, 1994, p. 135-137).

O que podemos notar ao longo da Antiguidade tardia é, de modo geral, uma ruptura com estas antigas delimitações: um processo gradual em que a antiga necrópole adentra a ci- 
4.Ainda que não haja um consenso nos debates sobre quais os edifícios seriam as duas igrejas em memória a Cipriano, podemos falar na importância da celebração de sua memória por dois fatores. $\mathrm{O}$ primeiro é por conta da existência de um sermão de Agostinho (Sermo 310) que faz referência de duas igrejas erigidas ao culto de Cipriano. O segundo é que, embora os edifícios que alguns autores alegam ser a segunda igreja em memória a Cipriano divirjam entre si, quaisquer que sejam, são construções ou do começo do século $\mathrm{V}$ (no caso de Bir Ftouha) ou mesmo do século IV (na sustentação de ser a igreja Damous el Karita). Isto é bem discutido em Leone (2007, p. 110-111). dade ou uma aproximação entre ambas, quer numa estrutura imaginativa, quer na organização de seus aspectos físicos. A partir da cidade de Cartago é possível observarmos algumas questões que essa longa transformação nos coloca, da mesma forma que podemos problematizá-las e nuançá-las.

O primeiro fenômeno a que nos atentamos foram as condições de implantação das igrejas cristãs na cidade. Segundo Anna Leone (2007, p. 109), a implantação das igrejas cristãs se desenvolveu, num primeiro momento, relacionada ao culto dos mártires e em áreas suburbanas durante o século IV, com foco maior na região norte da cidade. Com isto, podemos ter um breve parâmetro da importância da celebração dos mártires cristãos neste período, demonstrada na instauração dos núcleos de celebração, na continuidade e no aumento não só dos edifícios, como de uma posição valorativa que estes vão assumindo dentro da paisagem da cidade (BROWN, 1981). Isto pode ser visto, num aspecto amplo e breve, a partir da existência de duas igrejas construídas ao longo dos séculos IV e V, para celebrar a memória de Cipriano ${ }^{4}$, antigo bispo de Cartago.

Esta mesma importância pode ser observada na monumentalização das igrejas cemiteriais e martiriais ocorridas durante os períodos de ocupação vândala e bizantina. No período vândalo, podemos referir como exemplo a construção de uma igreja cemiterial na parte sul da cidade, conhecida hoje por Bir el Knissia. Esta mesma igreja foi, já no período bizantino, reformada e ampliada (LE lebração e da prática de enterrar os entes próximos junto aos mártires cristãos. Um grande exemplo é o complexo religioso de peregrinação conhecido como Bir Ftouha, no século VI (STEVENS, KALINOWSKI, van der LEEST, 2005). Além de atrair sepultamentos em seu interior e em seu entorno, o complexo também fomentou a circulação de pessoas nesta região da cidade. De modo semelhante, podemos citar o desenvolvimento de outra necrópole fora dos muros da cidade que teve uma longa duração em conexão com os sepultamentos cemiteriais: a basílica conhecida como Damous el Karita. Localizada na área norte da cidade, Damous el Karita permaneceu como um foco de sepultamentos ao longo dos séculos III-VI, apesar de sua provável contração de tamanho no final deste período (STEVENS, 2005, p. 3; LEONE, 2007, p. 157). 
Não podemos deixar de considerar a questão da importância da religiosidade cristã, de modo geral, e dos mártires, de modo específico, nas modificações da paisagem urbana em relação à topografia mortuária no Mediterrâneo Ocidental durante a Antiguidade tardia como um todo - embora captemos estas transformaçōes em diferentes maneiras, ritmos e regiōes (LEONE, 2007, p. 178). No entanto, um conjunto de outras modificações relacionadas às práticas mortuárias, desvinculadas ou não de uma religiosidade cristâ, pode ser visualizado nesse mesmo processo de modificação da cidade antiga. $\mathrm{O}$ traço marcante e característico disto que estamos dizendo são os sepultamentos dispersos dentro dos muros da cidade. De modo mais preciso: os sepultamentos dentro das cidades que não estão conectados - ou de que não há evidências que nos permitam afirmar isto - com um centro religioso (oratórios, igrejas, complexos episcopais).

Para vermos estes espaços de sepultamento dentro dos muros da cidade de Cartago, selecionamos três áreas específicas em que foram instalados: o odeão, o porto e o circo. A escolha destes locais parte de dois pressupostos gerais: 1) as características distintas de sepultamento que cada espaço apresenta; 2) por estarem instalados em antigos edifícios "definidores" da cultura e da economia da Cartago antiga e, mesmo, da Cartago da Antiguidade tardia.

A primeira região de que trataremos é a do antigo odeão. Como advertimos, esta é uma região de escavação do começo do século XX. Portanto, muitos dos dados fornecidos pelos vestígios lá encontrados são de difícil análise e avaliação. Mas podemos traçar, no mínimo, alguns aspectos relevantes da constituição deste espaço como uma área de sepultamentos. É provável que este antigo edifício de espetáculos já estivesse abandonado pouco antes da ocupação vândala de Cartago, em 439, embora seja difícil afirmar algo neste sentido. De qualquer maneira, o que mais nos chama a atenção é que, durante o período vândalo, o odeão já poderia ter sido ocupado como uma região mortuária. Algumas sepulturas foram encontradas para além de seu interior, no pórtico que o conectava ao teatro. Inclusive no teatro se desenvolveu um espaço de sepultamentos, com túmulos que podem ser datados de modos mais preciso num primeiro período bizantino, no decorrer do século VI. Mas, também é possível que o teatro 
tenha se constituído como uma região de sepultamentos durante o período vândalo (LEONE, 2007, p. 159).

É importante acrescentar que alguns arqueólogos acreditam que nesta região norte/nordeste da cidade tenha se desenvolvido um grande e organizado cemitério no período bizantino, conectado com vários edifícios religiosos (LEONE, 2007, p. 204). Pois, somados ao desenvolvimento destes dois espaços como áreas de sepultamentos, foram encontradas, a oeste desta mesma região, no interior e ao redor de duas domus abandonadas entre fins do século VI e início do VII, alguns túmulos. Acrescente-se a esta interpretação o fato desta regiāo estar localizada próxima ao Demerch, uma antiga área com vários edifícios religiosos. De qualquer modo, caso tenha existido ali um cemitério altamente organizado no período bizantino ou não, o que nos interessa é que o odeão, sem contar seus arredores, constituiu uma região de ampla utilização como área de sepultamentos no interior da cidade, mesmo que ainda permaneça a dúvida sobre as condições de sua implantação.

A segunda região de sepultamentos dentro dos muros da cidade que falaremos é de uma necrópole localizada próxima ao circo, no sudeste da cidade, que se constituiu como área de sepultamento durante o século VII. Não se sabe ao certo quando o circo parou de ser frequentado enquanto espaço de espetáculo, embora alguns autores sustentem que seu abandono definitivo possa ter ocorrido no século VII (LEONE, 2007, p. 206).

Cerca de cinquenta inumações foram encontradas nesta área. Elas datam do começo até a metade do século VII. Para Stevens, esta necrópole se adéqua a um padrão que se constituiu e disseminou durante este período tardio: este padrão é o dos "cemitérios administrados" ("managed cemeteries"). O termo "administração" é inferido por conta do nível de organização que esta necrópole apresenta. Os túmulos estão em uma disposição linear determinada, com certa padronização entre seus tipos. Outro fator que leva a autora caracterizar a necrópole desta maneira é o fato de que, mesmo que raras vezes identificadas, as localizações tumulares são conhecidas e a grande maioria não chega a ser violada (STEVENS, 2005, p. 4-5). Foram também encontradas três ânforas de inumação (LEONE, 2007, p. 207). 
No que tange às construções dos túmulos: todos os que foram encontrados, excetos os três sepultamentos realizados em ânforas, foram feitos em estruturas de pedras (stones cist). Todas as placas de pedra que compõem os túmulos foram espoliadas de outros edifícios, isto é, são produtos de reutilizaçōes de materiais de antigas estruturas. Quase todos estes blocos retirados de outras estruturas são simples, sem adornação. Porém, um caso excepcional foi encontrado: trata-se de um fragmento de um quadro que foi inserido numa parede tumular (LEONE, 2007, p. 208).

A reutilização teria sido um destino comum das estruturas de grande parte dos espaços de espetáculo espalhados por todo Império (WARD-PERKINS, 1999). Todavia, foram poucos os casos que acabaram reutilizados como áreas funerárias. Destino provável inclusive das estruturas do teatro, ou mesmo do odeão, de Cartago. Mesmo que não tenhamos nenhuma descrição pormenorizada dos tipos de sepulturas encontrados no interior destas estruturas (LEONE, 2007, p. 207).

A terceira e última área de sepultamento que escolhemos está localizada na região norte do porto circular, embora acrescentemos que enterros tenham também ocorrido na ilha do porto. Todos os sepultamentos realizados nesta área datam por volta do século VII (dentre o período de 625-650). Sete ou, bem admissível, oito túmulos de pedra foram encontrados. Este problema da quantidade de túmulos decorre do estado em que se encontrou o suposto oitavo túmulo: por conta da espoliação sofrida e de nenhum osso ter sido encontrado em seu interior. Seis destes túmulos estão localizados em cômodos adjacentes na parte oeste do sítio (HURST; DUHIG, 1994, p. 310). Estes cômodos são de edifícios que continuaram a ser ocupados durante e depois das instalações tumulares. Os túmulos devem ter sido instalados, segundo os autores, dentro da sequência de construção destes edifícios. Esta ocupação e seu uso posterior não funerário são alegados devido à similaridade da construção do piso e dos níveis de ocupação encontrados (HURST; DUHIG, 1994, p. 312).

As formas de enterramento encontradas nestes edifícios seguem um padrão formal, padrão que é bem semelhante aos sepultamentos realizados fora da cidade: são túmulos de pedra, em que os corpos são enterrados de modo profundo, 
suas cabeças estão no limite dos túmulos e de acordo com a sua orientação cardeal (HURST; DUHIG, 1994, p. 313). No interior dessas sepulturas foram encontrados vestígios de 10 indivíduos, distribuídos em seis túmulos. No sétimo não foram encontrados ossos, mas supõe-se que eles deterioraram ao longo do tempo (HURST; DUHIG, 1994, p. 310). Três destas sepulturas apresentam enterros múltiplos: na primeira, encontraram os corpos de um possível adulto e duas crianças; na segunda, estavam enterradas uma mulher e uma criança; na terceira, duas crianças enterradas em datas sucessivas (HURST; DUHIG, 1994, p. 313).

A partir desta região nós podemos perceber um tipo de sepultamento distinto dos anteriores: trata-se de sepulturas isoladas, no interior de construções ainda ocupadas. Além do fato de que tais construções estavam situadas em áreas de produção da cidade. Como estas, um grande número de sepulturas isoladas foi encontrado em toda cidade, embora seja difícil afirmar que todos os espaços em que se encontravam continuassem a ser utilizados sem nenhuma alteração em suas ocupações.

Nos primeiros espaços de sepultamento (o odeão e o circo) observamos enterros em áreas de antiga localização de edifícios públicos que, é bem possível, já estivessem em desuso. Outro ponto de destaque destes dois edifícios é a sua localização. Ambos estavam situados nas extremidades da cidade. No entanto, eles estavam conectados com áreas residenciais e é bem provável que, em sua função funerária, atendessem às suas respectivas regiōes - norte e sudoeste. Por último, evidenciamos a questão de que nestas duas áreas se formaram necrópoles organizadas, com uma média duração: mesmo com a falta de dados mais precisos, pode-se supor que o odeão tenha sido utilizado do século $\mathrm{V}$ ao fim do período bizantino, no século VII; e o circo durante o século VII.

Consideraçōes Finais: Questôes E INQuietaçōes QUe PERMANECEM

Embora os dados que apresentamos sejam poucos e a temporalidade utilizada seja extensa, algumas observaçōes gerais podem ser levantadas e problemas novos colocados. A primeira observação é que os sepultamentos dentro dos muros da 
cidade, em especial aqueles em áreas que continuam a ser ocupadas ou próximas de regióes habitacionais, tornam-se mais comuns nos períodos entre fins do século VI e início do século VII, com uma intensificação no decorrer deste último. No entanto, podemos observar este fenômeno dentro de um longo processo de transformação da paisagem urbana e mortuária, que pode ter seu marco referencial de ruptura na celebração dos mártires, do início do século IV. Isto não só devido aos motivos religiosos destes sepultamentos, mas também a uma possível ruptura nos sistemas de pensamento deste período, referentes aos modos de proximidade cada vez mais crescente com os mortos (BROWN, 1981, p. 1-22).

Além das questôes religiosas, muito se tem discutido a respeito da temática econômica e sua relação com a prática mortuária no interior das cidades. Diversos autores modernos questionam se esses sepultamentos, com ênfase aos isolados ou aos que não chegam a constituir uma área funerária comum, seriam ou não realizados por pessoas sem condições para sepultar seus mortos nas necrópoles extramuros. Outros autores, ao contrário, perguntam-se se, devido aos sepultamentos dentro das áreas urbanas serem, em sua grande maioria, realizados da mesma forma que nas necrópoles fora das cidades, não seriam estas tumbas urbanas privilegiadas, no interior de uma nova dinâmica com o espaço mortuário e com o espaço habitacional. ${ }^{5}$

A maior parte das discussões neste sentido enfatiza a correlação dos sepultamentos e o declínio da economia tardia. Entretanto, pudemos observar que a vida urbana continua ativa em determinadas áreas que se transformaram em espaços mortuários, inclusive em setores de produção da cidade e nos séculos mais tardios, como em fins do século VI e inícios do século VII. Deste modo, podemos arriscar em afirmar que, para além de exemplificar um colapso econômico, as práticas mortuárias na cidade de Cartago parecem como um dos componentes de transformação, do mesmo modo que são afetadas pelo conjunto de transformaçóes que ocorrem durante a Antiguidade tardia.

As mudanças econômicas, de fato, existiram. Contudo, acreditamos que não se puderam estabelecer novas práticas mortuárias apenas por este fator. Abre-se, assim, uma nova chave interpretativa ou um conjunto de novas interconexões
5. Embora Hurst e Duhig, no texto que trabalhamos aqui, façam as relações entre estas formas de sepultamento, eles não afirmam tal hipótese. Para esta discussão, ver em especial Leone (2007, p. 206-207). 
para estudar as relações entre práticas mortuárias e, nesse caso apontado, a economia tardia. Advertindo sempre que uma não é pura e simples consequência da outra, mas que ambas mantêm entre si fortes relaçôes, do mesmo modo que se relacionam com outros fatores, tais como socioculturais e políticos (SALLER, 2008). Assim, estamos próximos de investigar novas formas desenvolvidas para se relacionar e experienciar com os espaços citadinos. Diálogos passíveis de serem analisados em sua minúcia ao tomarmos a materialidade e a topografia mortuárias como meios ativos pelos quais as estruturas sociais são transferidas, restruturadas, realocadas ou mesmo desafiadas (FAHLANDER, OESTIGAARD, 2008).

Para realizar um estudo que busque correlacionar estes diversos fatores, é preciso estar atento às diferentes transformações e suas distintas velocidades e escalas ocorridas no Mediterrâneo Ocidental, durante e após o Império Romano. Buscar uma aproximação destes estudos com uma abordagem regional, como, por exemplo, a sugerida por Ward-Perkins (1998, p. 403-409), pode ser uma boa alternativa para futuras respostas acerca das práticas mortuárias e das mudanças nas cidades no decorrer dos séculos IV ao VII. E que essas novas abordagens levem em consideração não só a famigerada noção de "declínio e queda", mas que procure entender os processos, os conflitos, as narrativas e as ideias que morreram ou persistiram durante as disputas que estão envolvidas na construção e no fim dessas, então chamadas, cidades da Antiguidade tardia. Enfim, como Luke Lavan (2003a, p. 182-185) se esforça em realizar e reivindicar, tentarmos fazer com que os estudos sobre a topografia e as transformações das cidades se tornem espaços habitáveis de relações socioculturais e de relações de poder, inclusive no que tange às relaçôes para com a morte e os mortos.

\section{Agradecimentos}

O texto produzido para este artigo foi apresentado, numa versão anterior, no XXI Encontro da ANPUH-SP. Agradecemos às sugestôes, aos comentários e os incentivos enunciados pelos presentes naquela ocasião, em especial a Maria Cristina Kormikiari Passos e Silvana Trombetta pela organização do seminário temático. Agradecemos também às leituras e su- 
gestões de Julio Cesar Magalhães de Oliveira e Yasmin Carli Albino. Todavia, os argumentos desenvolvidos são de responsabilidade dos autores.

\section{REFERÊNCIAS BIBLIOGRÁFICAS}

BROGIOLO, G.P.; WARD-PERKINS, B. (Eds.). The idea and ideal of the town between late Antiquity and the early Middle Ages. Leiden: Brill, 1999.

BROWN, P. The cult of the saints: Its rise and function in Latin Christianity. Chicago: University of Chicago Press, 1981. . Antiguidade Tardia. In: História da Vida Privada: Do Império Romano ao ano Mil (Vol. I). Tradução de Hildebard Feist. São Paulo: Companhia das Letras, 1990, p. 225-300. . Pouvoir et persuasion dans l'Antiquité tardive. Vers um Empire chrétien. Paris, Seuil, 1998 (tradução de Pierre Chuvin da edição original de 1992).

CAMERON, A. The Mediterranean World in Late Antiquity AD 395-600. London, New York: Routledge, 1993.

CHADWICK, H. Augustine. Oxford: Oxford University Press, 2001 (1986).

CHRISTIE, N.; LOSEBY, S.T. Towns in transition: urban evolution in Late Antiquity and the Early Middle Ages. London: Scolar Press, 1996.

FAHLANDER, F; OESTIGAARD, T. The materiality of death: bodies, burials, beliefs. In: FAHLANDER, F. OESTIGAARD, T. The materiality of death: bodies, burials, beliefs. Oxford: Archaeopress, 2004. p. 1-16.

FUMADÓ ORTEGA, I. Cartago: historia de la investigación. Madrid: CSIC, Escuela Española de Historia y Arqueología en Roma, 2009.

FUNARI, P.P.A. A vida quotidiana na Roma antiga. São Paulo: Annablume, 2003.

Fontes arqueológicas: os historiadores e a cultura material. In: PINSKY, C. (Org.). Fontes Históricas. São Paulo: Contexto, 2006. p. 81-110.

FUNARI, P. P. A.; GARRAFFONI, R. S. Morte e vida na arena romana: a contribuição da teoria social contemporânea. Fênix, Uberlândia, v. 4, p. 1-15, 2007. 
GRANDAZZI, A. As origens de Roma. Trad. C. G. Colas. São Paulo: Ed. UNESP, 2010.

HURST, H.R. Excavations at Carthage: The British Mission. Vol. II, 1: The Circular Harbour, North Side; the Site and Finds other than Pottery. Oxford: Oxford University Press, 1994.

HURST, H.R.; DUHIG, C. "7th-century AD cist burials and other skeletal remains". In: HURST, H.R. Excavations at Carthage: The British Mission. Vol. II, 1: The Circular Harbour, North Side; the Site and Finds other than Pottery. Oxford: Oxford University Press, 1994.

IVISON, E.A. Burial and urbanism at Late Antique and Early Byzantine Corinth (c. AD 400-700). In: CHRISTIE, N.; LOSEBY, S.T. (eds.). Towns in transition: urban evolution in Late Antiquity and the Early Middle Ages. London: Scolar Press, 1996. p. 99-125.

JOHNSON, P.S. Economic evidence and the changing nature of urban space in late Antique Rome. Barcelona: Universitat de Barcelona, 2012.

LANCEL, S. Cartago. Barcelona: Crítica, 1994.

LAVAN, L. Late Antique Archaeology: an introduction. In: .; BOWDEN (eds.). Theory and practice in Late Antique Archaeology. Leiden, Boston: 2003, p. vii-xvi.

. Late antique urban topography: from archi-

tecture to human space. In: .; BOWDEN (eds.). Theory and practice in Late Antique Archaeology. Leiden, Boston: 2003a., p. 171-195.

LEONE, A. Changing townscapes in North Africa from Late Antiquity to the Arab conquest. Bari: Edipuglia, 2007.

MAGALHÃES DE OLIVEIRA, J.C. Travail, habitation et sociabilités populaires dans les villes de l'Afrique romaine: les quartiers commerçants et artisanaux de Carthage et de Timgad. In: FONTAINE, Souen; SARTRE, Stéphanie; TEKKI, Amel. (Org.). La ville au quotidien. Regards croisés sur l'habitat et l'artisanat antiques (Afrique du Nord, Gaule, Italie). Aix-en-Provence: Presses Universitaires de Provence, 2011. MAGALHÃES DE OLIVEIRA, J.C. Potestas Populi. Participation populaire et action collective dans les Villes de l'Afrique romaine tardive (vers 300-430 apr. J.C). Paris/Turnhout, Sorbonne/Brepols, 2012. 
MATTINGLY, D.J.; HITCHNER, R.B. Roman Africa: an archaeological review. The Journal of Roman Studies, Vol. 85, p. 165-213, 1995.

PUGLISI, G. Política e religione nel IV Secolo. Le prefetture Del 384 e Il 'Carmen contra paganos'. Catania, CUECM, 1981.

RIBEIRO, M. S. Arqueologia das práticas mortuárias: uma abordagem historiográfica. São Paulo: Alameda, 2007.

RICH, J. The city in late antiquity. London: Routledge, 1992. SALLER, R. Introduction. In: LAURIE BRINK, O. P.; GREEN, D. (eds.). Commemorating the dead: texts and artifacts in context: Studies of Roman, Jewish, and Christian burials. Berlin, New York: Walter de Gruyter, 2008. p. 1-7.

SMALL, D. B. The tyranny of the text: lost social strategies in current historical period archaeology in the classical Mediterranean. In: FUNARI, P.P.A.; HALL, M.; JONES, S. (eds.) Historical Archaeology: back from the edge. London, New York: Routledge, 1999. p. 122-136.

STEVENS, S. T.; KALINOWSKI, A. V.; van der LEEST, H. Bir Ftouha: a pilgrimage church complex at Carthage. Portsmouth, R.I.: Journal of Roman Archaeology, 2005.

STEVENS, S. T. The mortuary landscapes of Roman and post-Roman Carthage ( $1^{\text {st }}-7^{\text {th }}$ c. AD). University of Chicago, 2005. Disponível em <http://divinity.uchicago.edu/martycenter/conferences/thedead/private/stevens.pdf $>$. Acesso em: 7 de novembro de 2011.

WARD-PERKINS, B. The Cities. In: CAMERON, A.; GARNSEY, P. (eds.). The Cambridge Ancient History: Volume XIII, The late Empire, AD 337-425. Cambridge: Cambridge University Press, 1998, p. 371-410.

. Re-using the Architectural Legacy of the

Past, entre idéologie et pragmatism. In: BROGIOLO, G.P.; WARD-PERKINS, B. (Eds.). The idea and ideal of the town between late Antiquity and the early Middle Ages. Leiden: Brill, 1999. p. 225-244.

Recebido em março de 2014. Aprovado em julho de 2014. 
